\title{
Case report. Size does matter: acuut nierfalen door een te groot pessarium
}

\author{
Pieter Verpoort ${ }^{1} \mathbb{D} \cdot$ Bart Schrier $^{2}$
}

Published online: 4 July 2018

(c) The Author(s) 2018

\section{Samenvatting}

Een 88-jarige patiënt kwam naar de Spoedeisende Hulp met postrenaal nierfalen en bilaterale hydronefrose. Deze bleken te worden veroorzaakt door een te groot pessarium dat externe druk uitoefende op beide distale ureters. Na verwijdering van het pessarium herstelde de nierfunctie zich volledig. In vijf eerdere case reports over hydronefrose door vreemde voorwerpen in de vagina werd deze veroorzaakt door pessaria (3), een seksueel object van onbekende origine en een vibrator. Slechts één case report beschrijft een bilaterale hydronefrose die wordt veroorzaakt door een pessarium.

Trefwoorden vaginaal vreemd voorwerp $\cdot$ pessarium $\cdot$ acuut nierfalen $\cdot$ obstructieve uropathie

\section{Case report. Size does matter: acute kidney failure due to pessary size}

\begin{abstract}
An 88-year-old patient presenting herself with acute renal failure was found to have an obstructive uropathy with bilateral hydronefrosis. This was caused by an oversized pessary blocking the distal ureters. After removal of the foreign body the kidney function recovered. In the literature there are five case reports about vaginal obstruction causing hydronephrosis. Three were due to a pessary, one to a sexual object of unknown origine and one to a vibrator. Only one case report describes bilateral hydronephrosis due to a pessary.
\end{abstract}

Keywords vaginal foreign body $\cdot$ pessary $\cdot$ acute kidney failure $\cdot$ obstructive uropathy

\section{Introductie}

Vaginale voorwerpen en in het bijzonder pessaria zijn zeldzame oorzaken van postrenale obstructie. Het doel van deze studie was om een zeldzame casus te presenteren en na te gaan of er in de literatuur vergelijkbare casussen zijn beschreven.

\footnotetext{
dr. Pieter Verpoort verpoortpieter@gmail.com

1 Universitair ziekenhuis Gent, Gent, België

2 Jeroen Bosch ziekenhuis, 's-Hertogenbosch, Nederland
}

\section{Casus}

Een 88-jarige dame kwam 's avonds naar de Spoedeisende Hulp na een ongelukkige val thuis. Traumatische en cardiale controle waren geruststellend. Buiten een beroerd gevoel dat al de hele dag aanwezig was, had de patiënt geen andere klachten. De laatste zes maanden voelde ze zich in het algemeen wat minder fit en ze was in dat halve jaar ook al zes kilo afgevallen. Urologisch kwam pollakisurie naar voren zonder dysurie. De huisarts had reeds een infectie uitgesloten en ter behandeling vesicare opgestart, die wegens toenemende misselijkheid snel weer was stopgezet. Lichamelijk onderzoek liet geen bijzonderheden zien: patiënte maakte geen zieke indruk, had een soepel abdomen en ook nierslagpijn was bilateraal afwezig. De bloeduitslag liet als afwijking een acute nierinsufficiëntie zien met een creatinine van $445 \mu \mathrm{mol} / \mathrm{l}$, een GFR van $8 \mathrm{~mL} / \mathrm{min} / 1,73 \mathrm{~m}^{2}$ en een ureumgehalte van $30 \mathrm{mmol} / \mathrm{L}$. Deze waarden waren in mei 2015 nog normaal. Verder sloten we elektrolieten- 

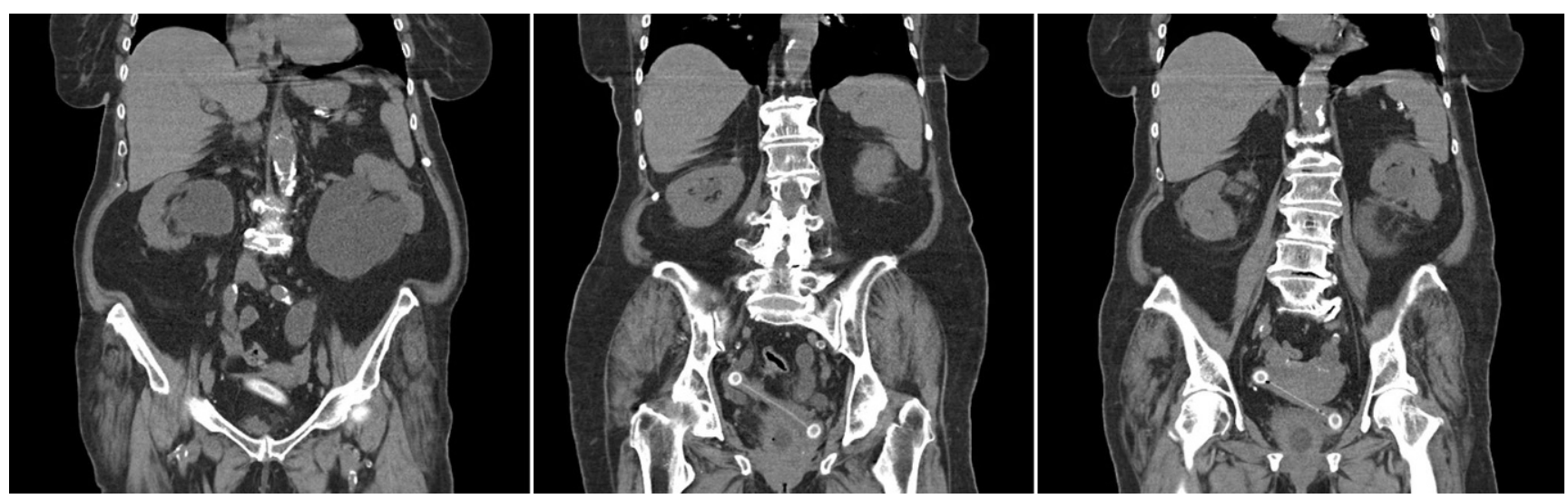

Figuur 1 CT-scan: serie van drie blanco coronale beelden

stoornissen uit met een kaliumgehalte van $5,8 \mathrm{mmol} / \mathrm{l}$ en natriumgehalte van $127 \mathrm{mmol} / \mathrm{L}$. Een echogram van de nier en de blaas toonde zeer forse hydronefrose beiderzijds met cortexverlies, en dilatatie tot in het kleine bekken, waar meer structuren te zien waren, mogelijk de uterus of een ruimte-innemend proces (RIP). Dit beeld was vrij onduidelijk. De blaas was asymmetrisch en redelijk gevuld. De blaaswand kon niet goed beoordeeld worden (deze zou onregelmatig kunnen zijn). Het obstruerend moment was dus niet met zekerheid aantoonbaar. De diagnose luidde: acute postrenale nierinsufficiëntie met bilateraal een forse ureterohydronefrose ten gevolge van het ruimte-innnemende proces in het klein bekken. Gezien de afwezigheid van flankpijn betrof dit waarschijnlijk een reeds langer bestaand progressief proces. De combinatie van leeftijd, vermagering, bilaterale obstructie, een onduidelijk RIP in het kleine bekken en een langer bestaand proces neigde naar maligniteit.

Gezien het nachtelijk uur werd ervoor gekozen om verdere beeldvorming de volgende dag te verrichten. Het was

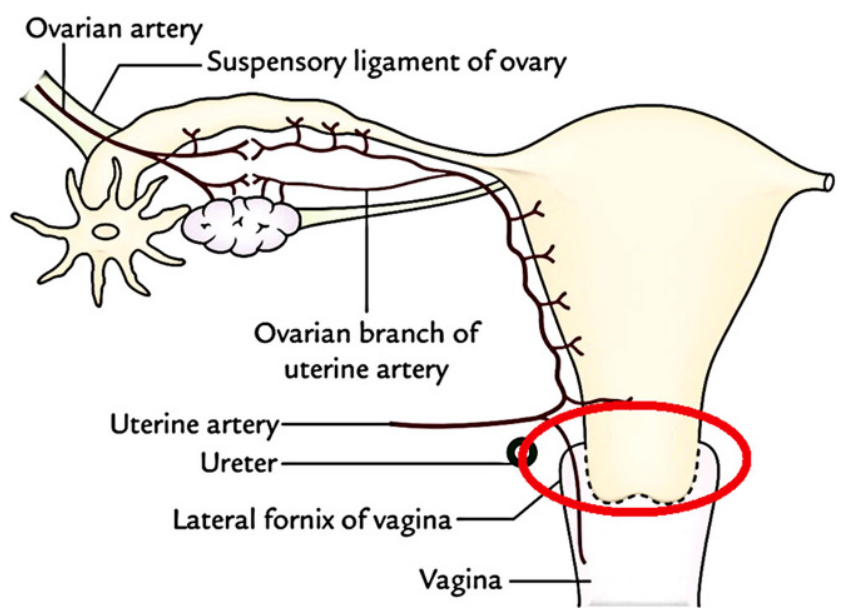

Figuur 2 Schets van het mechanisme met in het rood het pessarium dat de ureter comprimeert ter hoogte van de junctie (aangepast naar een tekening van https://www.earthslab.com/anatomy/uterus/) een optie om beiderzijds nefrostomiekatheters te plaatsen om de obstructie op te heffen en de nierfunctie te optimaliseren. Dan zou de volgende dag een CT-scan met intraveneus contrast mogelijk zijn. Echter, gezien de hoge maligniteitsverdenking leek het verstandiger afwachtend te zijn met interventies. Een 88-jarige patiënte, die zich momenteel comfortabel voelde, zou wel eens weinig baat kunnen hebben van een lange oncologische lijdensweg. De patiënte werd opgenomen op de afdeling nierziekten met de uroloog als medebehandelaar. De dag daarop werd een blanco CT afgenomen (fig. 1).

De CT-scan toonde forse hydronefrose beiderzijds, links meer dan rechts, met gedilateerde ureters die te vervolgen waren naar het klein bekken waar een obstructie te zien is. Dit betrof echter geen oncologisch proces in het kleine bekken, maar een (te groot) pessarium, dat externe druk uitoefende op beide ureteren (fig. 2). Het pessarium was ongeveer zes maanden daarvoor bij de patiënt geplaatst door haar gynaecoloog. Omdat hierdoor de verzakkingsklachten verdwenen, was door de gynaecoloog geen verdere controle gepland. Na het verwijderen van het pessarium klaarde de nierfunctie bij de patiënt snel weer op tot een GFR van $45 \mathrm{~mL} / \mathrm{min} / 1,73 \mathrm{~m}^{2}$. Volledig herstel bleef echter uit.

\section{Discussie}

Het dragen van een pessarium gedurende een lange periode, kan vaginale infectie, afscheiding, ulceratie en, minder frequent, vaginale fistulae veroorzaken [1]. Door een te grote angulatie of druk op de vesico-ureterale junctie kan een pessarium ook hydro-ureteronefrose veroorzaken. In de literatuur zijn vijf case reports gepubliceerd over patiënten die zich presenteerden met vreemde voorwerpen in de vagina die hydro-ureteronefrose veroorzaakten: drie pessaria, één voorwerp van onbekende origine en één vibrator [2-6]. 


\section{Conclusie}

Deze casus beschrijft een extreem zeldzaam, maar potentieel levensbedreigende situatie van postrenale obstructie die wordt veroorzaakt door een te groot pessarium. Bilaterale hydronefrose bij een pessarium is eenmaal in de literatuur beschreven. Het verwijderen van het obstructieve moment is in zo'n geval de oplossing. Gezien de ernst van een dergelijke situatie lijkt het raadzaam bij nieuw ontstane urinaire klachten steeds de recente urogenitale ingrepen in het achterhoofd te houden, zelfs als deze zo banaal lijken als het plaatsen van een pessarium.

Open Access This article is distributed under the terms of the Creative Commons Attribution 4.0 International License (http:// creativecommons.org/licenses/by/4.0/), which permits unrestricted use, distribution, and reproduction in any medium, provided you give appropriate credit to the original author(s) and the source, provide a link to the Creative Commons license, and indicate if changes were made.

\section{Literatuur}

1. Thakar R. Pessaries for treatment of pelvic organ prolapse and incontinence. In: Rogers R, Sung WV, Thakar R, Iglesia C, redactie. Female Pelvic Medicine and Reconstructive Surgery: Clinical Practice and Surgical Atlas. Columbus: McGraw-Hill Education Ltd; 2013. pag. 339-52.

2. Dasgupta P, Booth CM. Uremia due to ureteric obstruction of a solitary kidney by a vaginal pessary. Scand J Urol Nephrol. 1996;30:493-4.

3. Duncan LE, Foltzer M, O'Hearn M. Unilateral hydronephrosis, pyelonephritis, and bacteremia caused by a neglected vaginal ring pessary. J Am Geriatr Soc. 1997;45:1413-4.

4. Meinhardt W, Schnitemaker NW, Smeets MJ, Venema PL. Bilateral hydronephrosis with urosepsis due to neglected pessary. Scand J Urol Nephrol. 1993;27:419-20.

5. Heintz J, Chason J, Kramer A. Bilateral ureteral obstruction caused by vaginal foreign body: A case report. Can J Urol. 2009; 16:4870-2.

6. Donaldson JF, Tait C, Rad M, Walker S, et al. Obstructive uropathy and vesicovaginal fistula secondary to a retained sex toy in the vagina. J Sex Med. 2014;11(10):2595-600. Oct.

dr. Pieter Verpoort aios urologie

dr. Bart Schrier uroloog 